\title{
CLARIFICATION OF PUBLIC TRANSPORT USAGE CONDITIONS IN AHMEDABAD, INDIA
}

\author{
TAKASHI HIRAIDE, TOMOYA KAWASAKI \& SHINYA HANAOKA \\ School of Environment and Society, Tokyo Institute of Technology, Japan
}

\begin{abstract}
Ahmedabad, India, has serious traffic congestion problems in peak periods. This is mainly due to the use of cars and motorcycles. The usage of public transport, consisting of a bus system called "AMTS" and a rapid transit bus called "BRTS", represented only a 12\% modal share in Ahmedabad in 2011. This study explores the conditions underlying the non-use of public transport and its feeders among car and motorcycle owners in Ahmedabad. We conducted a household questionnaire survey that gathers respondents' subjective impressions of public transport and its feeder services in the suburban areas of Ahmedabad in December 2017. A Transport Unacceptance Model is developed based on the Technology Acceptance Model 2 using structural equation modelling based on the collected samples. We reveal that the "no advantage to use" among the owners of cars and motorcycles has the highest effect on the non-use of AMTS among the latent variables, followed by "burden to use". The observed variables "effort to transfer" and "effort of route choice" significantly affect the "burden to use" latent variable. "Burden to use" regarding auto-rickshaws has a relatively strong effect on the non-use of AMTS. This implies that improving feeder services (i.e. the connectivity between auto-rickshaws and AMTS) is important for enhancing the use of AMTS. As for BRTS, "burden to use public transport (i.e. ticketing system)" and "auto-rickshaw" have the strongest effects among the latent variables. Several negative impressions of auto-rickshaws as a feeder service are observed in both AMTS and BRTS. Particularly, subjective norms such as "family and friends do not use auto-rickshaw" are influential on the non-use of public transport.
\end{abstract}

Keywords: public transport, feeder, auto-rickshaw, technology acceptance model 2, structural equation modelling, Ahmedabad.

\section{INTRODUCTION}

The population of Ahmedabad is increasing along with economic growth. It became India's fifth largest city in 2011. The number of registered vehicles in Ahmedabad has also increased rapidly, causing economic losses and environmental problems due to the severe traffic congestion. To solve those problems, the Bus Rapid Transport System (BRTS) began operating in 2007, while the bus transport network called the "Ahmedabad Municipal Transport Service” (AMTS) began in 1947. However, these public transport systems accounted for only $12 \%$ of modal share in the city, whereas private vehicles accounted for $36 \%$ in 2011 [1]. Shifting private vehicle users to buses is one way to improve this situation. Thus, it is necessary to analyse the conditions that private vehicle owners do not use public transport and its feeder transport. This city has a paratransit transport system called "Autorickshaw" (Auto), which is expected to serve as a feeder for public transport. It is possible that little modal shift is being observed because of both the buses and their feeders.

Previous studies on public bus transport services at the national and local levels in India have mainly focused on productivity, efficiency, demand, pricing, financial viability, restructuring, impact on congestion, air pollution, and carbon dioxide emissions [2]-[13]. Few studies have explored the conditions that people do not use public transport or its feeders in Indian cities [14], and no study has examined Auto as a feeder transport mode of public transport. Therefore, this study explores the conditions underlying the non-use of public transport and its feeders among car and motorcycle owners in Ahmedabad. 
Table 1: Modal Share in Ahmedabad in 2011 [1].

\begin{tabular}{|l|r|}
\hline Private & $36 \%$ \\
\hline Public transport & $12 \%$ \\
\hline Non-motorised modes & $46 \%$ \\
\hline Intermediate public transport, auto & $6 \%$ \\
\hline Total & $100 \%$ \\
\hline
\end{tabular}

\section{TRANSPORT SYSTEM IN AHMEDABAD}

The transport system in Ahmedabad is dependent on roadway systems. Several transport modes constitute urban transport, and its modal share is shown in Table 1.

The share of private modes (motorcycles and cars) in Ahmedabad is high. As Table 1 shows, $36 \%$ of the trips in this area are taken via private modes. They constitute around $90 \%$ of the total registered vehicles in the city. The private vehicle population stands at 1.77 million (263,000 cars and 1.5 million motorcycles). Both modes are growing at $8 \%$ per annum, and four-wheelers have more than doubled during the last decade. Motorcycles are the most popular mode, accounting for a third of all trips in the city [1]. This is one of the causes of congestion at the centre of the city.

Public transport in Ahmedabad consists of AMTS and BRTS. As Table 1 shows, this accounts for only $12 \%$ of all trips in the city. Figs 1 and 2 show the AMTS vehicles and bus stops. There are 827 buses with 174 routes and 1,688 bus stops. The total network is $550 \mathrm{~km}$ long and has a ridership of 600,000 passengers per day. AMTS bus stops are located on the kerbsides of roads and are a mixture of signposts and temporary structures.

Fig. 3 shows a BRTS bus and bus station. BRTS is operated by Ahmedabad Janmarg Limited, which is registered under the Companies Act 1956 and is a subsidiary of the Ahmedabad Municipal Corporation. BRTS began in 2009 and currently covers $86 \mathrm{~km}$ with 131 bus stations. The system functions with segregated bus lanes, median bus stations, level boarding and alighting, high frequency (two to five minutes), low fares, and a real-time passenger information system. It has a ridership of 125,000 passengers per day. BRTS stations have median locations, high plinths $(900 \mathrm{~mm})$, at-grade approaches, off-board ticketing facilities, and tensile wires around their exterior. Most of these stations are located near junctions and have synchronized signal phasing for pedestrians [15]. Passengers buy their ticket at a counter, scan the QR code at the turnstile of a bus stop, and take a bus.

Fig. 4 shows Auto vehicles. Auto is an intermediate public transport mode operating in

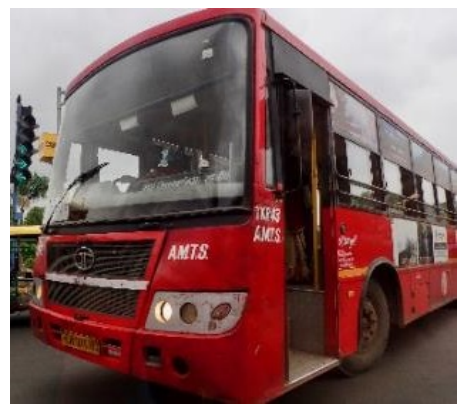

Figure 1: AMTS bus.

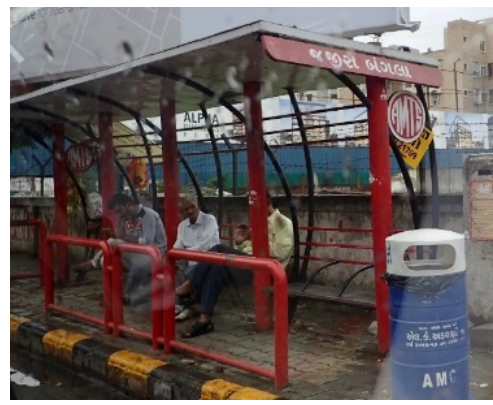

Figure 2: AMTS bus stop. 


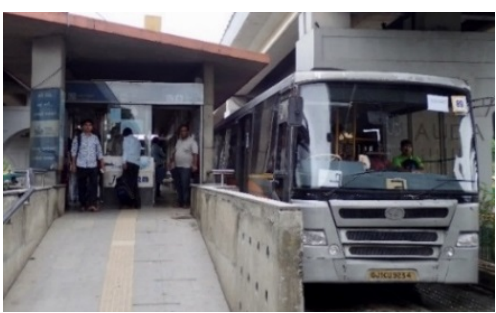

Figure 3: BRTS bus and bus stop.

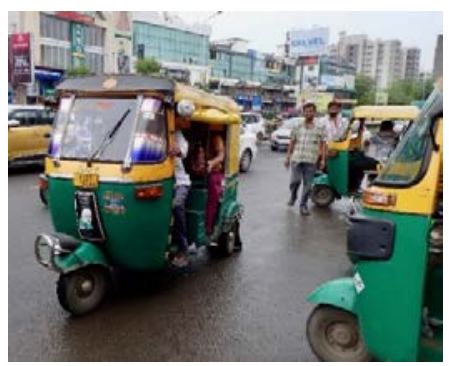

Figure 4: Auto in Ahmedabad.

the city. As Table 1 shows, it accounts for $6 \%$ of all trips in Ahmedabad. Their population is growing at $11 \%$ per annum [1]. They are expected to play a role as a feeder for public transport.

\section{METHODOLOGY}

The model is developed based on the Technology Acceptance Model 2 (TAM2). Encouragement is necessary for private vehicle users to shift to public transport. We should understand any negative impressions they might have of public transport and its feeders. Thus, we develop the model to clarify the conditions that the owners of cars and motorcycles do not use public transport or its feeders.

\subsection{Technology Acceptance Model 2}

This study employs TAM2, a model for explaining the usage behaviour of information systems based on structural equation modelling (SEM) developed by Venkatesh and Davis [17]. The structure of TAM2 is shown in Fig. 5. TAM2 is an extended version of TAM, which can express perceived usefulness and usage intentions in terms of social influence and cognitive instrumental processes. TAM2 incorporates additional theoretical constructs spanning social influence processes (subjective norm, voluntariness, and image) and cognitive instrumental processes (job relevance, output quality, result demonstrability, and perceived ease of use). Both are used to explain and predict user acceptance of information systems. The conceptual structure of TAM 2 assumes that "perceived usefulness" and "perceived ease of use" are fundamentally important in explaining service use. Perceived usefulness is the degree to which a person believes that using a particular system enhances his/her performance. Perceived ease of use is the degree to which a person believes that using a particular system is free from effort [16].

\subsection{Transport Unacceptance Model}

TAM2 is used to identify particular beliefs and test the propositions that respondents have particular impressions of a new technology and thus they use it due to those impressions. In this study, we use a contraposition model, in which we assume that respondents do not use a new technology and thus they have no particular impressions of it. We assume the Transport Unacceptance Model is developed based on that TAM2 can be applied to discover what is unacceptable conditions to users. 


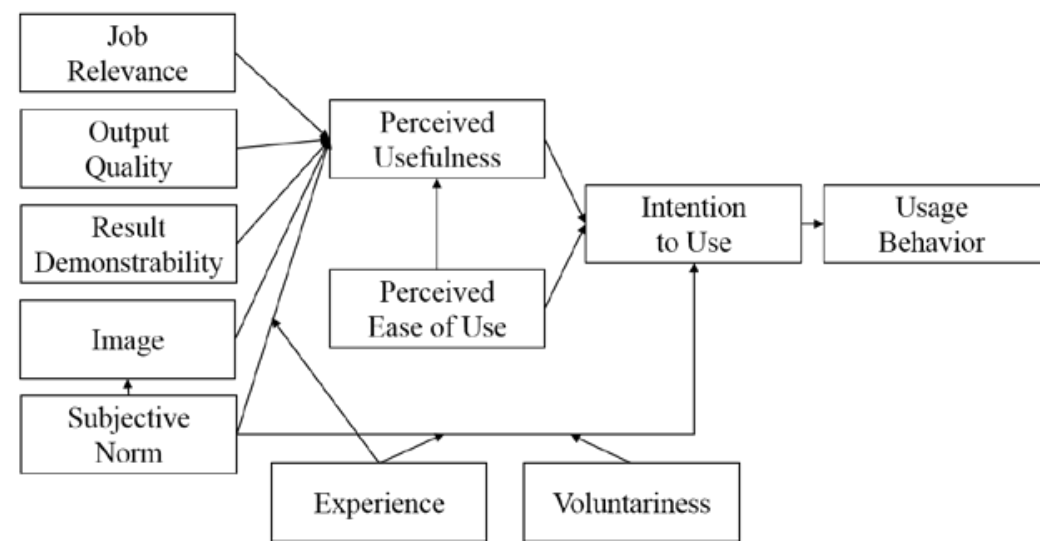

Figure 5: Structure of Technology Acceptance Model 2 (TAM 2) [17].

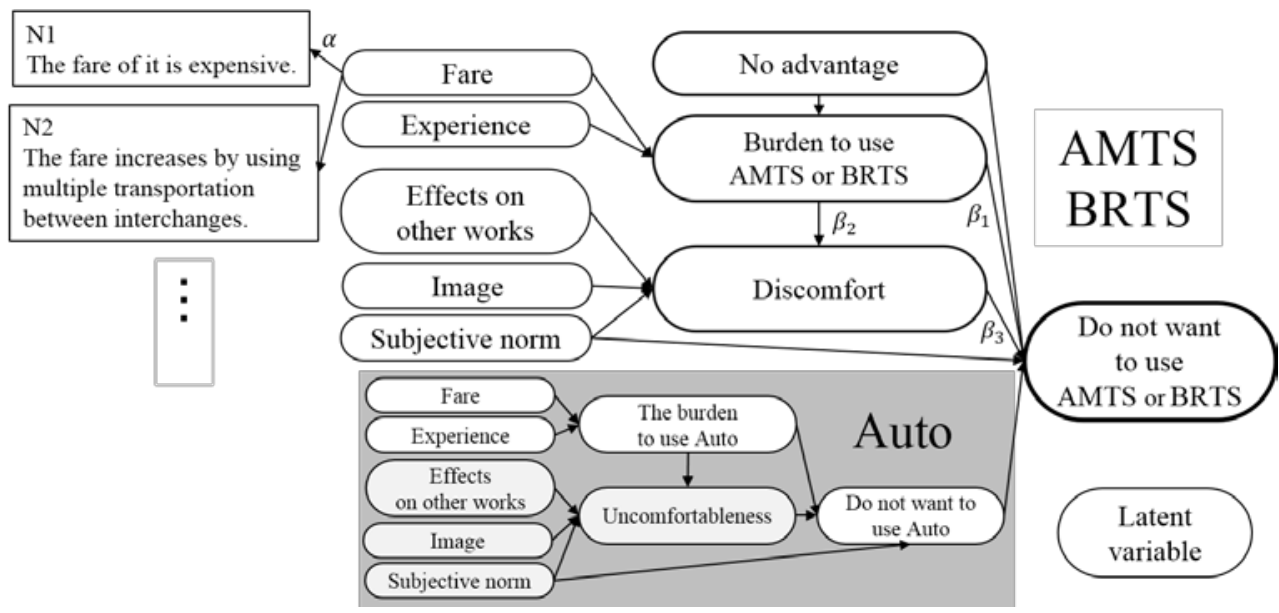

Figure 6: Path diagram of Transport Unacceptance Model.

The non-use of transport modes is explored using several impressions towards public transport. For instance, a person may have the impression that public transport offers no advantage. Others might feel discomfort with public transport. Based on these assumptions, a path diagram reflecting the decision making structure by which non-users' decision making leads to the non-use of public transport and Auto is developed by employing TAM2, as shown in Fig. 6. In this path diagram, it is assumed that impressions of Auto influence the use of the bus service.

Direct path coefficients are calculated by the following equations:

$$
\begin{array}{lc}
\text { Measurement equation } & x_{i j}=\alpha_{i j} \cdot y_{i}+\zeta_{i j}, \\
\text { Structural equation } & y_{i}=\sum_{n} \beta_{n i} \cdot y_{n}+\xi_{i},
\end{array}
$$


where $x_{i j}$ reflects the observed variables and the answers to the questionnaire. $y_{i}$ reflects the latent variables, such as "Fare", "No advantage", and "Do not want to use AMTS or BRTS". $\alpha_{n i}$ and $\beta_{i j}$ are direct path coefficients of the latent variables, and $\zeta_{i j}$ and $\xi_{i}$ are error variables. In explaining the non-use of each transport mode, besides the effects of the direct path, there are also indirect effects via other latent variables. For example in Fig. 6, $\beta_{1}$ is the direct path from the latent variable "Burden to use AMTS or BRTS" to that of "Do not want to use AMTS or BRTS". In addition, the latent variable "Burden to use AMTS or BRTS" influences "Do not want to use AMTS or BRTS" indirectly via the influence of "Discomfort". This means that $\beta_{2}$, the path coefficient from "Burden to use AMTS or BRTS" to "Discomfort", and $\beta_{3}$, the path coefficient from "Discomfort" to "Do not want to use AMTS or BRTS" also have some influence. This is calculated by multiplying $\beta_{2}$ and $\beta_{3}$ together. Thus, total effects $\gamma$, the sum of the direct and indirect path coefficients, are the estimation results. For example, the total effects $(\gamma)$ from "Burden to use AMTS or BRTS" to "Do not want to use AMTS or BRTS" as shown in Fig. 6 is calculated as follows:

$$
\gamma=\beta_{1}+\beta_{2} \beta_{3}
$$

\subsection{Rating items of questionnaire}

The perceived usefulness and ease of use of public transport is defined by the subjective belief of the user, which is the core concept of TAM 2. Venkatesh and Davis [17] used the rating scale method to measure these constructs. In this study, the model analyses the nonuse of two bus services (i.e. AMTS and BRTS) and Auto as a feeder using a four-point rating scale. The rating items and the latent variables are shown in Table 2. The rating items were modified with reference to the evaluation items of TAM 2 in order to be applied to the nonuse of public transport in Ahmedabad. These were verified for relevance and validity based on a preliminary survey conducted with researchers of CEPT University in Ahmedabad.

\section{QUESTIONNAIRE SURVEY}

A questionnaire survey was conducted on the owners of car and motorcycle in December 2017. Fig. 7 shows the survey area. It is located in the northwestern suburbs of the city outside of 132 Feet Ring Road. The southeastern part of the city has many narrow roads, and bus systems perform poorly there. The survey area is divided into Area A and B. The former is within $500 \mathrm{~m}$ of the AMTS route, covering the inside of the hinterland of AMTS bus stops but outside that of BRTS bus stops. The latter is within $500 \mathrm{~m}$ of both AMTS and BRTS routes, covering inside the hinterland of both AMTS and BRTS bus stops.

The survey was conducted on December 16 and 17 of 2017 with the cooperation of 25 students of CEPT University. They visited residential areas in the survey area and interviewed residents and filled in the survey forms with their responses. Respondents were asked to answer each question on a four-point scale, reflecting the variables for the non-use of public transport and Auto (4 and 1 indicate "strongly agree" and "strongly disagree", respectively). In all, 297 samples in Area A and 295 samples in Area B are collected in two days. After the descriptive analysis, the model was developed based on TAM2, and it was analysed via SEM.

The ratio of male to female respondents in both areas is about 8 to 2. It is assumed that the results do not differ depending on gender. Area B has a larger proportion of residents and higher age, higher educational backgrounds, and higher incomes. 
Table 2: Rating items of questionnaire.

\begin{tabular}{l}
\hline AMTS and BRTS \\
Fare \\
\hline [N1] The fare is expensive. \\
\hline [N2] The fare increases when using multiple \\
transport between interchanges. \\
\hline Burden to use AMTS or BRTS
\end{tabular}

[N3] It takes time and effort to choose the route.

[N4] Getting on and off is troublesome.

[N5] It does not come often, so it is hard to take it.

[N6] It takes time and effort to transfer between it and other transport.

[N7] I do not like the drivers' attitude.

[N8] It does not operate in early morning or after midnight.

[N9] It is hard to carry luggage.

\begin{tabular}{l}
\hline [N10] Ticketing system is complicated. \\
\hline Experience \\
\hline [N11] I have less experience using it. \\
\hline Effect on other works \\
\hline [N12] It is hard to work/talk while moving in a \\
bus. \\
\hline [N13] Its operation is uncertain because of traffic \\
congestion. \\
Discomfort
\end{tabular}

[N14] It tends to get involved in traffic accidents.

[N15] It tends to get involved in harassment.

[N16] It is dirty, so it is not comfortable. [N17] There is less space, it feels congested.

[N18] It is crowded, so it is not comfortable

[N19] AC is not installed or not working well, so it is not comfortable.

[N20] It is difficult to board and unboard during monsoons.

[N21] I do not want to sit next to a stranger.

Image

[N22] It is for the people who cannot afford private modes.

[N23] It is not preferable because it is a vehicle with a large environmental burden.

\begin{tabular}{l}
\hline Subjective norm \\
\hline [N24] We have never used it in my family. \\
\hline [N25] Most of my colleagues and friends have \\
never used Auto to commute. \\
\hline No advantage \\
\hline [N26] I do not feel the advantage of it. \\
\hline
\end{tabular}

Auto as feeder

Fare

[M1] The fare of Auto is expensive.

[M2] Autos have a night charge system and it is expensive.

\section{Burden to use AMTS or BRTS}

[M3] It takes time and effort to reach the nearest bus stop from my location

[M4] It takes time and effort to explain the route to Auto drivers.

[M5] It is difficult to step into and out of Auto.

[M6] Auto are not frequently available.

[M7] It takes time and effort to interchange

between Auto and other transport.

[M8] I do not like Auto drivers' attitude.

[M9] Autos don't operate in the early morning and after midnight.

[M10] It is difficult to carry luggage.

[M11] It takes time and effort to negotiate fares.

Experience

[M12] I have less experience using Autos.

\section{Effect on other works}

[M13] It is hard to work/talk while moving in Auto, because they drive rashly.

[M14] Auto's operation is uncertain because of traffic congestion.

\begin{tabular}{l}
\hline Discomfort \\
\hline [M15] Autos tend to get involved in traffic \\
accidents. \\
\hline [M16] Autos tend to get involved in harassment. \\
\hline [M17] Autos are old and unmaintained. \\
\hline [M18] Auto is small, it feels congested. \\
\hline [M19] Auto is noisy, so I feel unpleasant. \\
\hline [M20] I am exposed to the outside conditions \\
like rain, dirt, and air pollution. \\
\hline [M21] I do not want to sit next to strangers. \\
\hline Image \\
\hline [M22] Autos are for the people who cannot \\
afford private modes.
\end{tabular}

[M23] Autos are a burden on the environment.

\begin{tabular}{l}
\hline Subjective norm \\
\hline [M24] We have never used Auto in my family. \\
\hline [M25] Most of my colleagues and friends have \\
never used Auto to commute. \\
\hline
\end{tabular}




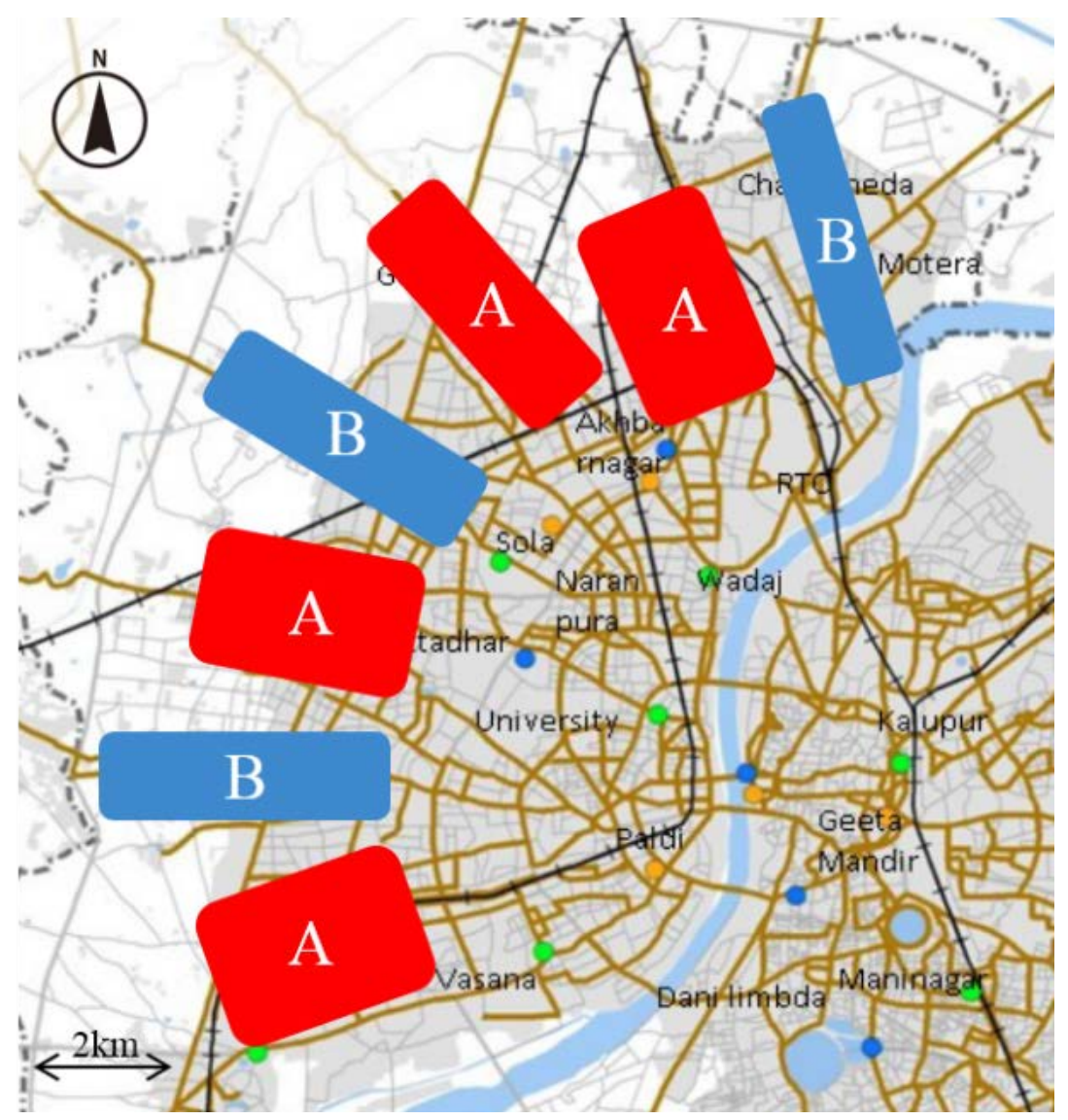

Figure 7: Map of Area A and Area B in the city of Ahmedabad.

\section{RESULTS AND DISCUSSION}

The data collected from the questionnaire survey for each area and bus service were input to the model, and the path coefficients were estimated as shown in Figs 8-10. IBM SPSS Amos 25 Graphics was used for the estimation of the unknown parameters of SEM. Parameters with a p-value of 0.05 or more were excluded from the model in order to increase robustness. Latent variables without significant paths to observable variables were also excluded. An acceptable goodness of fit index (GFI) is generally considered to be 0.7 or more. The models do not fit well. However, each model has as many as 40 observable variables; thus, the degree of freedom has increased, and the conformity between the model and the data has declined. Toyoda [18] argued that "the value of GFI should be considered important only if the number of observable variables is up to 30". The root mean square error of approximation (RMSEA) of each model is less than 0.1, falling within the allowable range. Thus, both models for AMTS and BRTS can be considered valid. The conditions for the non-use of public transport and Auto are discussed based on the results. The signs of all the path coefficients of $\alpha_{n i}$ are as expected. Path coefficients between latent variables $\beta_{n i}$ show direct effects. We use the sum of the total effects in the analysis. 


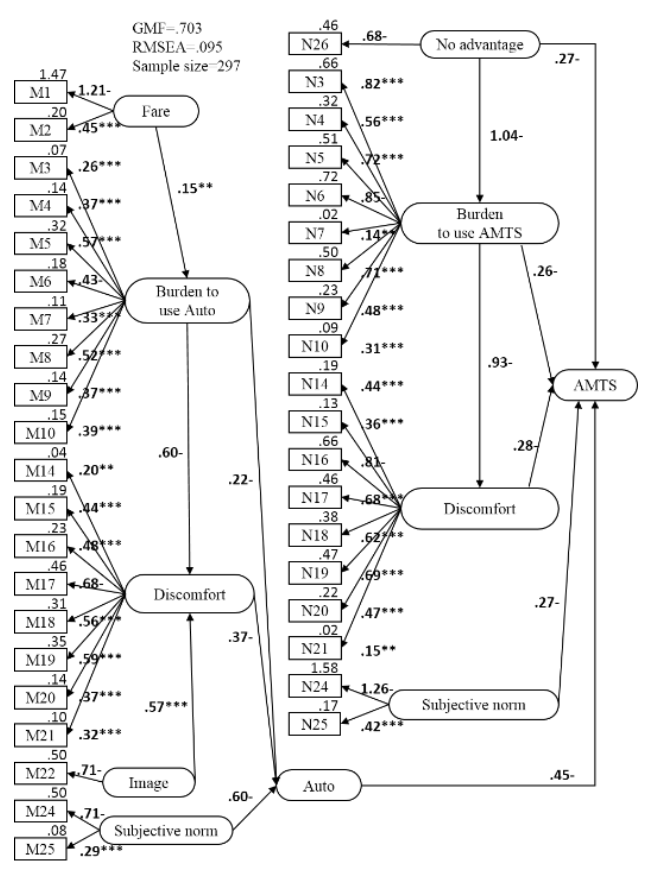

Figure 8: Area A AMTS/Auto.

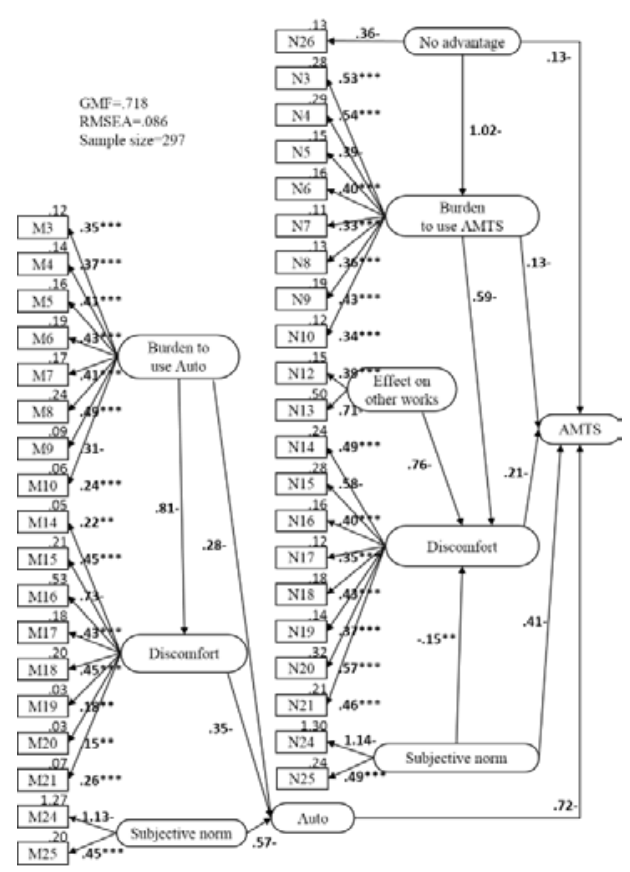

Figure 9: Area B AMTS/Auto.

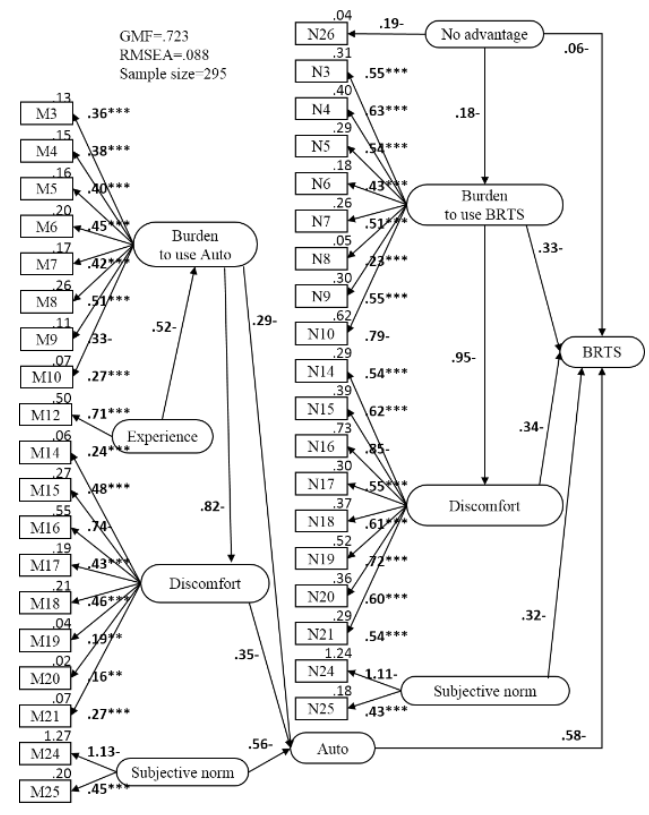

: Observed variable : Latent variable

- : fixed parameter of non-standardized coefficients **: $0.001 \leqq \mathrm{p}$-value $<0.05$ ***: p-value $<0.001$

Figure 10: Area B BRTS-Auto. 


\subsection{Area A: AMTS}

The results of the path diagram for AMTS in Area A are shown in Fig. 11. It shows the amount of the total effect of the latent variables on the non-use of AMTS in Area A. "No advantage" has the greatest influence. This means that the residents feel that private vehicles are more convenient or comfortable for their trips. Moreover, "Burden to use AMTS" also has an influence on the non-use of AMTS. The observable variables, such as "N3: It takes time and effort to choose the route" and "N6: It takes time and effort to transfer between it and other transport" have large values. This means that AMTS must make it easier to transfer to other transport forms and routes. Moreover, "N5: It does not come often, so it is hard to take it" and "N8: It does not operate in early morning or after midnight" also have large values, showing that residents consider the operating hours and frequency to be unsuitable.

The results of the path diagram for Auto as a feeder of AMTS are shown in Fig. 12. Impressions of Auto affect the non-use of AMTS. The subjective norms about Auto have the greatest influence on the non-use of Auto and AMTS. The behaviour of friends and/or family greatly affects users' decision making. The influence of "The burden to use Auto" and "Discomfort" has also a great influence on the non-use of Auto. Observable variables such as M5 and M17 to M19 have large values, indicating that poor vehicle performance and driver attitude are influential.

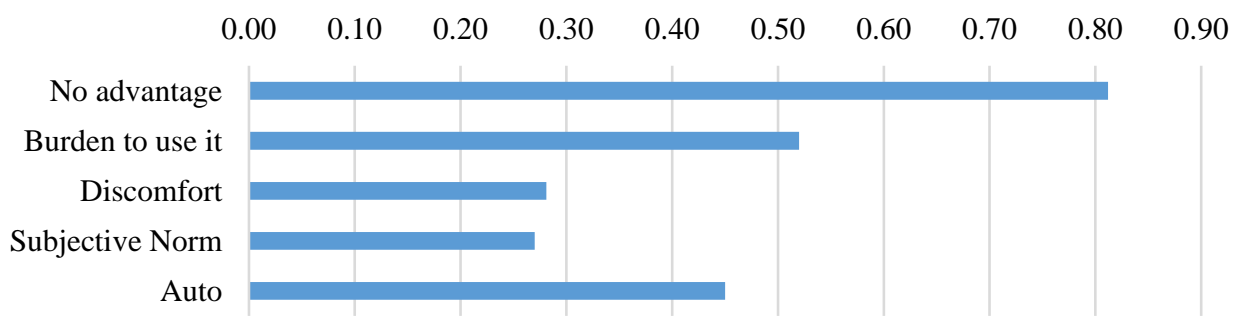

Figure 11: Total effect of latent variables on the non-use of AMTS in Area A.

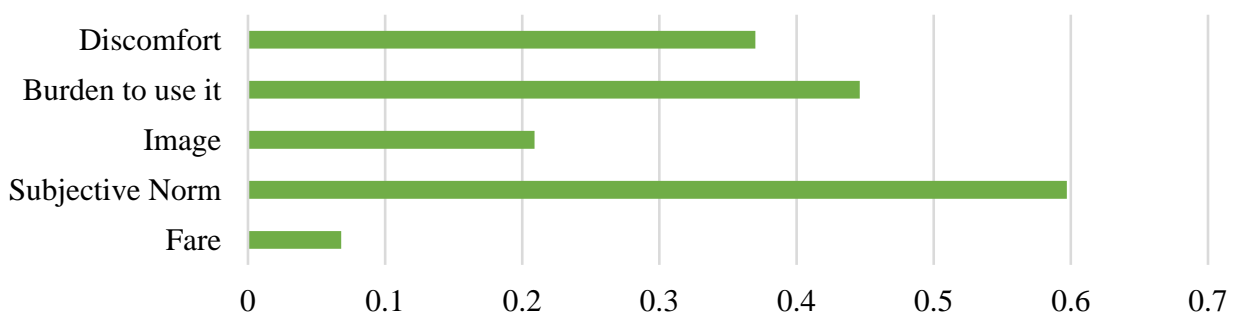

Figure 12: Total effect of latent variables on the non-use of Auto in Area A. 


\subsection{Area B: AMTS}

The result of the path diagram for AMTS in Area B is shown in Fig. 13. It shows the total effect of the latent variables on the non-use of AMTS in Area B. The non-use of AMTS is affected by impressions of its feeder, rather than by impressions of AMTS itself.

The results of the path diagram for Auto as a feeder of AMTS is shown in Fig. 14. The most influential latent variable on the non-use of Auto is the subjective norms, as for Area A; "the burden to use Auto" is also influential. According to the observable subjective norm variables, the residents are dissatisfied with the drivers' attitude, the routes, and negotiating fares, which leads them to not use Auto or buses. "Discomfort" has two thirds the influence the other latent valuables have. "M16: Autos tend to get involved in harassment" has the greatest influence on "Discomfort". This means that the residents in Area B are more sensitive to the risk of being involved in crimes while riding public transport than are residents in Area A. This might be because Area B has more residents with higher incomes and education levels.

\subsection{Area B: BRTS}

The results of the path diagram for BRTS in Area B are shown in Fig. 15. It shows the total effect of the latent variables on the non-use of BRTS in Area B. "Burden to use BRTS" has the greatest influence on the non-use of BRTS. Observable variables N3, N4, and N10, reflecting the difficulty of determining routes, getting on and off the bus, and purchasing tickets, have a strong influence from "Burden to use BRTS". Thus, using the bus should be made easier. Furthermore, the value of the path coefficient "N8: It does not operate in early morning or after midnight" is also large, indicating that residents have the impression that BRTS does not run often in the morning and after midnight. Impressions of Auto also affect impressions of BRTS.

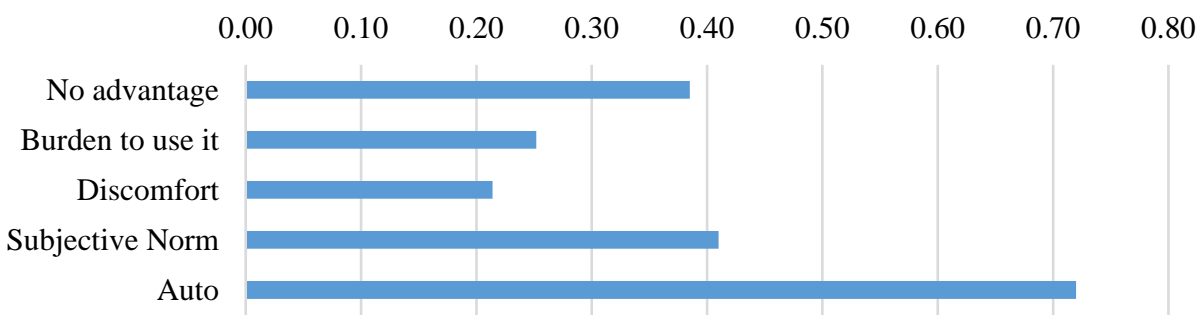

Figure 13: Total effect of latent variables on the non-use of AMTS in Area B.

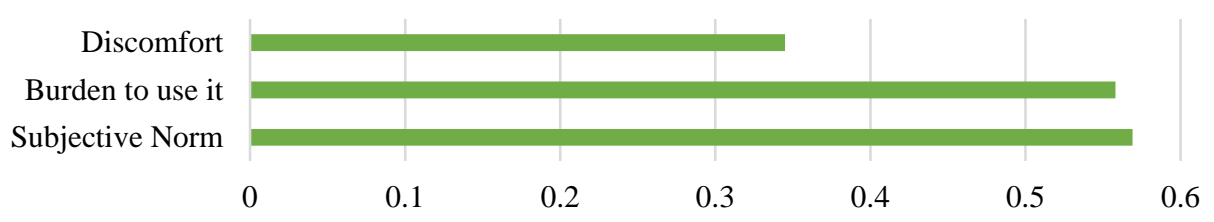

Figure 14: Total effect of latent variables on the non-use of Auto in Area B. 


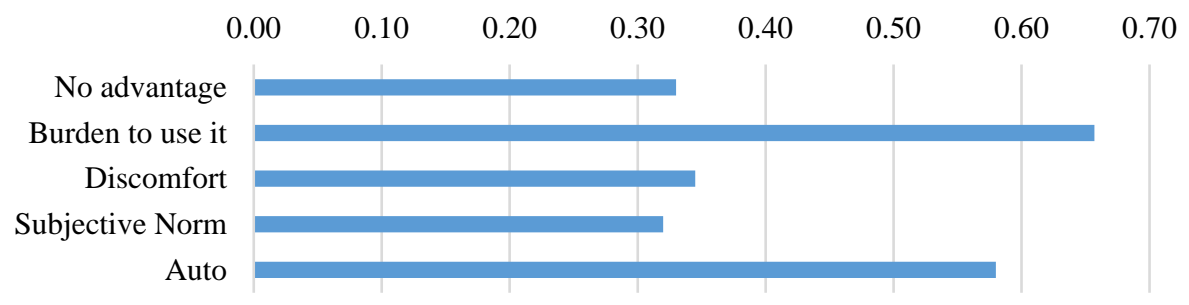

Figure 15: Total effect of latent variables on the non-use of BRTS in Area B.

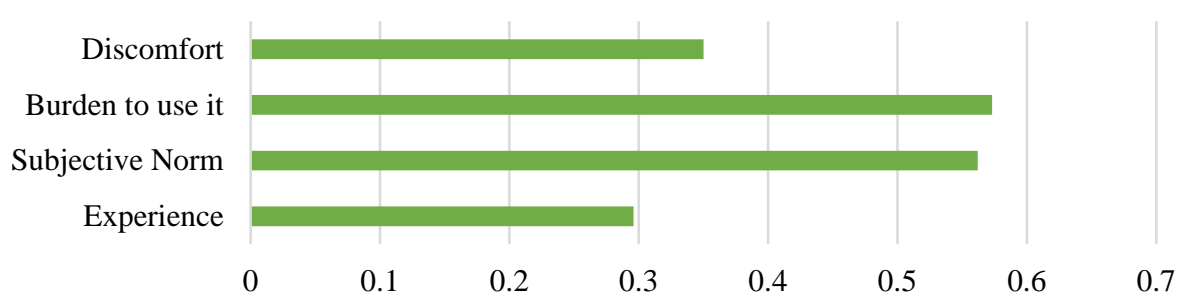

Figure 16: Total effect of latent variables on the non-use of Auto in Area B.

The path diagram for BRTS feeders is shown in Fig. 16. "The burden to use Auto" and subjective norms have a strong influence on the non-use of Auto. One of the influential latent variables is "The burden to use Auto". The influence of observable variable M8 shows that drivers' service quality must be improved. The impression that Autos are hard to catch is also dissuading people from using BRTS. Subjective norms are as influential as "The burden to use Auto". Thus, the behaviour of those close to residents greatly affects their decision making. The path coefficient of "Discomfort" is also large. Thus, the residents of Area B are sensitive to the risk of being involved in crimes.

\section{CONCLUSION}

We analyse the impressions vehicle users in Ahmedabad have of public transport and its feeder systems. The results show that the feeling of "no advantage to use" has the greatest effect on the non-use of AMTS among the latent variables, followed by "burden to use". Observable variables "effort to transfer" and "effort of route choice" affect latent variable "burden to use". The "burden to use" auto-rickshaws has a relatively strong effect on the nonuse of AMTS. This implies that improving the feeder service (i.e. the connectivity between Auto and AMTS) is important for enhancing the use of AMTS. As for BRTS, "burden to use public transport (i.e. ticketing system)" and "auto-rickshaw" have the greatest effect among the latent variables. Several negative impressions of auto-rickshaws as a feeder service are observed concerning both AMTS and BRTS. Subjective norms such as "family and friends do not use auto-rickshaws" are identified as influential conditions for the non-use of public transport. These findings should be considered in the planning for and implementing of more efficient and less burdensome city traffic. Nevertheless, it is unknown to what extent residents will modally shift after improvements are made. Therefore, it is necessary to create a policy based on the results of this study and to conduct a demonstration experiment. 
ACKNOWLEDGEMENT

This work was supported by JSPS KAKENHI Grant Number JP15H02632.

\section{REFERENCES}

[1] CoE, Urban Transport-CEPT University and Ahmedabad Urban Development Authority, Integrated Mobility Plan for Greater Ahmedabad Region, 2013.

[2] Badami, M.G. \& Haider, M., An analysis of public bus transit performance in Indian cities. Transportation Research Part A: Policy and Practice, 41(10), pp. 961-981, 2007. DOI: 10.1016/j.tra.2007.06.002.

[3] Deb, K., \& Sundar, S., Restructuring urban public transport in India. Journal of Public Transportation, 5(3), pp. 85-102, 2002. DOI: 10.5038/2375-0901.5.3.5.

[4] Pucher, J., Peng, Z., Mittal, N., Zhu, Y. \& Korattyswaroopam, N., Urban transport trends and policies in China and India: Impacts of rapid economic growth. Transport Reviews, 27(4), pp. 379-410, 2007. DOI: 10.1080/01441640601089988.

[5] Pucher, J., Korattyswaroopam, N. Mittal, N. \& Ittyerah, N., Urban transport crisis in India. Transport Policy, 12(3), pp. 185-198, 2005.

DOI: 10.1016/j.tranpol.2005.02.008.

[6] Pucher, J., Korattyswaroopam, N. \& Ittyerah, N., The crisis of public transport in India: Overwhelming needs but limited resources. Journal of Public Transportation, 7(3), pp. 95-113, 2004. DOI: 10.5038/2375-0901.7.3.5.

[7] Schipper, L., Banerjee, I. \& Ng, W., Carbon dioxide emissions from land transport in India: Scenarios of the uncertain. Transportation Research Record: Journal of the Transportation Research Board, 2114(1), pp. 28-37, 2009. DOI: 10.3141/2114-04.

[8] Singh, S. K., An inquiry into the cost structure of state transport undertakings in India. Transport Policy, 32, pp. 1-8, 2014. DOI: 10.1016/j.tranpol.2013.12.003.

[9] Singh, S.K., Urban transport in India: Issues, challenges, and the way forward. European Transport, 52, pp. 1-26, 2012.

[10] Singh, S.K., Road traffic crashes: The scourge of UP's cities. Economic and Political Weekly, 44(48), pp. 22-24, 2009.

[11] Singh, S.K., Review of urban transportation in India. Journal of Public Transportation, 8(1), pp. 79-97, 2005. DOI: 10.5038/2375-0901.8.1.5.

[12] Singh, S.K., An analysis of economic profitability of municipal transport undertakings in India. Indian Journal of Transport Management, 26(4), pp. 535-557, 2002.

[13] Tiwari, G., Urban transport priorities: Meeting the challenge of socio-economic diversity in cities: A case study of Delhi, India. Cities, 19(2), pp. 95-103, 2002. DOI: 10.1016/S0264-2751(02)00004-5.

[14] Singh, S., Assessment of passenger satisfaction with public bus transport services: A case study of Lucknow city (India). Studies in Business and Economics, 11(3), pp. 107-128, 2016. DOI: 10.1515/sbe-2016-0039.

[15] Shivanand, S., Madhav, P. \& Shelly, K., Commuters' exposure to PM2.5: Case study in Ahmedabad, India. Transportation Research Board 94th Annual Meeting, 2015.

[16] Nakamura, M., Human behavior model in information system use: A study on TAM. Chukyo Keiei Kenkyu, 10(2), pp. 51-77, 2001.

[17] Venkatesh, V. \& Davis, F.D., Theoretical extension of the technology acceptance model: Four longitudinal field studies. Management Science, 46(2), pp. 186-204, 2000. DOI: $10.1287 / \mathrm{mnsc} .46 .2 .186 .11926$.

[18] Toyoda, H., Notes for discussion of structural equation modeling. Kodo Keiryogaku, 29(2), pp. 135-137, 2012. DOI: 10.2333/jbhmk.29.135. 